\title{
COBERTURA VACUNAL EN ESPAÑA
}

José Luis de la Torre Misiego.

La primera vacuna antisarampión autorizada en España lo fue en 1965 y, como consecuencia, empezó a ser comercializada a través de Oficinas de Farmacia.

Simultáneamente, la Dirección General de Sanidad realizó con esta vacuna campañas piloto en algunas provincias españolas. Sin embargo, los resultados no fueron satisfactorios, ya que no fueron infrecuentes las reacciones adversas similares al cuadro clínico producido por la infección natural e, incluso, se dieron algunos casos de encefalitis postvacunal.

Evidentemente, estos resultados provocaron el rechazo generalizado de médicos y padres hacia esta vacuna, lo que obligó al laboratorio fabricante a retirarla del mercado en 1969.

En 1975 se autorizó en España una nueva vacuna atenuada, cuyo componente era la cepa Schwartz. En 1978 el Ministerio de Sanidad la incluyó en el calendario de vacunaciones, para su administración a niños de 9 meses de edad.

No obstante, hubo una escasa aceptación de la vacuna por parte del personal sanitario y de los padres, probablemente debido al recuerdo de la experiencia de la vacunación en los años 60, a lo que se pudo añadir el conocimiento de varios casos de encefalitis postvacunal en Inglaterra en 1969. El resultado fue una bajísima cobertura vacunal que en el año 1978 no superó el 4\% y que en 1981 era de $29 \%$.

En 1981 se realizó otra modificación del calendario de vacunaciones. En el nuevo calendario se incluye la vacuna triple vírica a los 15 meses de edad, en lugar de la antisarampión monovalente a los nueve meses.

La nueva vacuna triple vírica tuvo gran aceptación entre pediatras y padres. Como consecuencia, la cobertura vacunal pasó del $29 \%$ en 1981 al $47 \%$ en 1982 . En 1986 se alcanza por primera vez en España una cobertura vacunal media del $80 \%$ y desde 1993 , dicha cobertura no ha bajado del $90 \%$.

En la figura 1 puede observarse la evolución de la cobertura desde 1978 a 1997. Las flechas verticales indican los momentos más importantes en la evolución de la cobertura de vacunación contra el sarampión: 1978: Inclusión de la vacuna en el calendario de vacunaciones. 1981: Sustitución de la vacuna monovalente por vacuna triple vírica. 1986: Por primera vez se alcanza una cobertura de 80\%. 1993: A partir de ese año la cobertura vacunal no baja de $90 \%$.

A principio de los 80 , algunos países, sobre todo en el norte de Furopa, comenzaron a administrar una segunda dosis de vacuna antisarampión a edades que oscilan entre los 6 y 12 años. En España, la primera Comunidad Autónoma que inició esta estrategia fue Cataluña en 1988. Paulatinamente, otras Comunidades Autónomas fueron también incluyendo la segunda dosis en sus calendarios. En todos los casos, la segunda dosis de vacuna triple vírica sustituía en el calendario a la vacuna monovalente de rubeola que sólo se administra a niñas.

En 1994, doce Comunidades Autónomas administraban la segunda dosis de vacuna triple vírica. 
Figura 1

Sarampión. España: 1978-1997

Incidencia anual y cobertura de vacunación

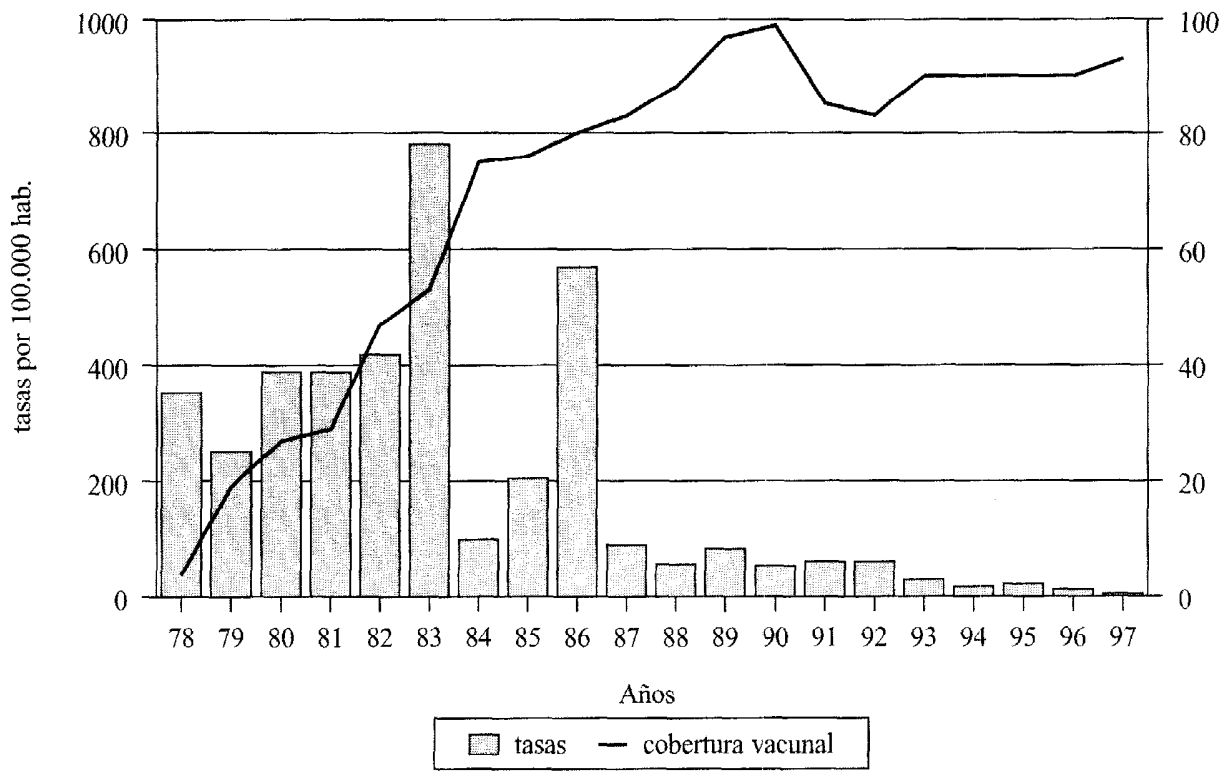

Un año más tarde, en 1995, el Consejo Interterritorial del Sistema Nacional de Salud aprobó un nuevo calendario de vacunaciones que contemplaba la administración de la segunda dosis de vacuna triple vírica a edades que oscilaban entre los 11 y los 13 años (tabla 1). Como consecuencia, las cinco Comunidades Autónomas más Ceuta y Melilla, que anteriormente aplicaban una sola dosis, iniciaron la estrategia de dos dosis.

En el año 1997, último del que se disponen datos, solamente una Comunidad Autónoma tiene una cobertura inferior al $80 \%$, mientras que ocho de ellas superan el $95 \%$.

Tabla 1

Consejo Interterritorial del Sistema Nacional de Salud Calendario de vacunaciones recomendado (1998)

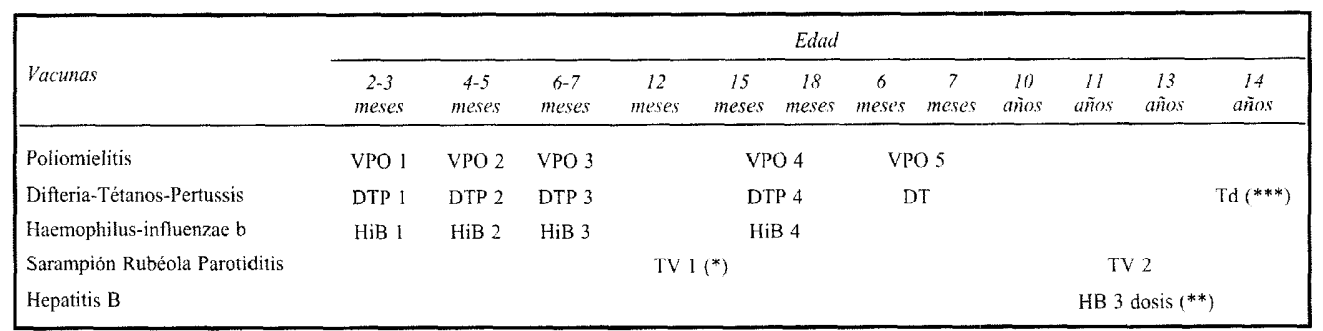

${ }^{*}$ En situación de especial tiesgo una dosis a los 9 meses o antes.

(**) También se vacunarán recién nacidos cuando las Autoridades Sanitarias lo estimen oportuno, asi como a los recién nacidos hijos de madre portadora y a los grupo de riesgo.

(***) Se aconseja proceder a la revacunación cada 10 años. 